OPEN ACCESS

Edited by:

Michela Di Trani,

Sapienza University of Rome, Italy

Reviewed by:

Jian $L i$,

Beijing Normal University, China

Alessia Renzi,

Sapienza University of Rome, Italy

*Correspondence:

Yuesheng Huang

huangys@hnfnu.edu.cn

Specialty section:

This article was submitted to

Health Psychology,

a section of the journal

Frontiers in Psychology

Received: 13 May 2021 Accepted: 31 August 2021 Published: 06 October 2021

Citation:

Yin $X$, Wang D, Li Z and Huang Y (2021) Psychological Difficulties Mediate and Self-Efficacy Moderates the Relationship Between Family Cumulative Risk and Hope Among Chinese Children From Low-Income Families. Front. Psychol. 12:709320. doi: 10.3389/fpsyg.2021.709320

\section{Psychological Difficulties Mediate and Self-Efficacy Moderates the Relationship Between Family Cumulative Risk and Hope Among Chinese Children From Low-Income Families}

\author{
Xiayun Yin ${ }^{1}$, Dongfang Wang ${ }^{2}$, Zhihua $\mathrm{Li}^{1}$ and Yuesheng Huang ${ }^{3 *}$ \\ ${ }^{1}$ Department of Psychology, Hunan University of Science and Technology, Xiangtan, China, ${ }^{2}$ College of Psychology, South \\ China Normal University, Guangzhou, China, ${ }^{3}$ Department of Psychology, Hunan First Normal University, Changsha, China
}

This longitudinal study investigated the role of psychological difficulties and selfefficacy in the relationship between family cumulative risk and hope among children from low-income families. The participants were 392 Chinese children from lowincome families; the study extended for 2 years, and participants completed data that were collected with the following questionnaires: the Family Cumulative Risk Index, Children's Hope Scale, Strengths and Difficulties Questionnaire-Difficulties subscale, and General Self-efficacy Scale. The results demonstrated that psychological difficulties played a mediating role in the relationship between family cumulative risk and hope; specifically, family cumulative risk predicted hope of children via psychological difficulties. Self-efficacy moderated the relationship between psychological difficulties and hope. This moderation supported "a drop in the ocean effect"; the protective effect of high self-efficacy worked only when psychological difficulties were at low levels. When psychological difficulties were at high levels, the buffering effect of self-efficacy on family cumulative risk was gradually weakened and eventually lost.

Keywords: family cumulative risk, psychological difficulties, self-efficacy, hope, children from low-income families

\section{INTRODUCTION}

In 1986, the Chinese government implemented a compulsory education policy-that it upholds to this day-providing education for grades 1 to 9 at no cost and requiring children to attend school through at least ninth grade. Nonetheless, many students drop out of junior high school each year. Economic factors have been regarded as a major cause for dropping out of school (Brown and Park, 2002). Indeed, poverty has been significantly correlated with dropout behavior (Mo et al., 2013; Wang et al., 2015), mainly owing to high tuition costs post-ninth grade in China. Among impoverished rural Chinese students, one study upheld that $14 \%$ of the students had left school in the first month of ninth grade (Yi et al., 2012). Moreover, low-income households have been associated with poor health and increased risk for mental health problems, and these can persist throughout childhood and adulthood of an individual (Hodgkinson et al., 2017). 
Children from low-income families generally experience higher rates of mental health problems and unmet mental health needs (Wadsworth and Achenbach, 2005). We, accordingly, felt this warranted an in-depth examination of the development and adaptation of Chinese children from low-income families; this knowledge may be useful for stakeholders to enhance support and intervention provisions, ensuring that these children have more opportunities to succeed in adulthood.

The concept of hope has been early theorized as a cognitive process concerning the desire of an individual to achieve clear and meaningful goals, generating motivation and strategies to ultimately achieve success (Snyder, 1995, 2002). This implies that systematic studies on hope among adolescents could yield important outcomes to the theoretic field and society. In adolescents, hope showed positive effects on one's academic and psychological aspects, academic achievement (Gallagher et al., 2017), and the buffering effects against negative psychological issues (Arnau et al., 2007). It also showed protective effects against school dropouts (Masten et al., 2008). Consequently, we rationalized that improving hope in children from low-income families could improve their academic development and protect their mental health.

The major influencing factor of hope in children is the family environment (Yin et al., 2019). In low-income scenarios, this factor may be further detrimental to children's hope development. Based on the family stress model, low-income families generally entail less-educated parents (Burlaka et al., 2015), parent-child communication, and parental participation (Asfour et al., 2017), and the adoption of negative parenting styles is not uncommon (Weitkamp and Seiffge-Krenke, 2019). Accordingly, children in low-income scenarios often face numerous adversities and multiple family risk factors simultaneously (Boe et al., 2018), and they commonly incur more adverse psychological outcomes (Burlaka et al., 2017).

Still, we thought that by focusing on low-income families, the multiple risk factors they may face, and their common effects, we could find ways to ensure the provision of greater consistency to children in these families. Specifically, a theory on the cumulative effect of risk factors on children suggests that a child's experience of a single risk does not necessarily lead to adverse developmental outcomes; however, upon experiencing multiple risk factors simultaneously, the probability of adverse outcomes greatly increases (Evans et al., 2013). Hence, we calculated the multiple family risks faced by children based on the cumulative risk model; this model proposes that, for a child's individual development, the total number of risk categories children face is more significant than the frequency and duration of a single risk factor (Evans et al., 2013). In this model, the calculation method requires each risk factor to be evaluated individually; if a specific risk is high, it is coded as 1 , while if it is low or risk-free, it is coded as 0 . Then, all risk factor scores are combined to determine the cumulative ecological risks next; the sum of all risk factors is totaled, facilitating the understanding and discussion of risk levels. The cumulative risk model showed a good prediction ability regarding the development outcomes of disadvantaged children (McLaughlin and Sheridan, 2016). Therefore, we deemed it of great value for our purpose to construct a multicomponent family cumulative risk (FCR) index and explore its impact on the hope of children.

The literature supports the idea that family risk can significantly predict adolescent psychological difficulties. In China, a cross-sectional study showed that FCR was associated with an increased emotion dysregulation and a decreased adaptive emotion regulation (Gao and Han, 2016). A crosscultural study found a substantial connection between adolescent mental health and experiencing parental anxious rearing and psychological control (Weitkamp and Seiffge-Krenke, 2019). Previous studies have shown that emotional problems can significantly affect the level of hope of an individual for the future (Ouweneel et al., 2012). Hope is an important trait for children from low-income families to experience to face the future, and this feeling may be affected by their current level of psychological adaptation (Snyder, 2002). Hence, FCR seemingly influences the level of hope in children and the current and future mental health of a child.

Meanwhile, positive psychological resources, such as selfefficacy and self-esteem, could buffer the negative effects of ecological risk on the mental health of adolescents (Wright et al., 2013). Conceptually, self-efficacy refers to the overall confidence of an individual in the capacity to cope with various challenges/new situations (Schwarzer, 1994), being a major psychological influencing factor of hope levels (Snyder, 2002; Davidson et al., 2012). Corroborating, a study showed that high self-efficacy could promote confidence in the abilities of an individual, opportunity-seeking behavior for knowledge/skill improvement, and higher hope levels (Barrows et al., 2013). Moreover, self-efficacy, as a protective resource, is an important moderator in various settings (Heuven et al., 2006); exemplifying, individuals with high self-efficacy were more likely to adapt to/overcome risks or adversities, while those low in self-efficacy were more likely to incur adverse psychological outcomes (Bosmans et al., 2015). If an individual exhibits a high level of self-efficacy, he will have clearer goals and be able to achieve them more effectively. Resultantly, his level of hope would be higher. On the contrary, if the self-efficacy level of an individual is low, their goal will seem unclear. This may contribute to a lack of motivation in the pursuit of achieving his goal, resulting in a lower level of hope (Phan, 2013).

This study aimed to analyze the longitudinal relationship between FCR, psychological difficulties, self-efficacy, and hope in Chinese children from low-income families. We hypothesized that there would be a mediating effect of psychological difficulties on the relationship between FCR and hope and self-efficacy would play a moderating role in this model.

\section{MATERIALS AND METHODS}

\section{Participants}

In November 2017, we conducted the baseline survey (Time 1, T1). Through convenience sampling, 504 seventh-grade children from low-income families were recruited; they came from 12 junior high schools in six cities in Hunan Province, China. In March 2018, participants from the T1 group were recruited for the follow-up survey (Time 2, T2). In November 2018, 
participants from the T2 group were recruited for the follow-up survey (Time 3, T3). In July 2019, participants from the T3 group were recruited for the final follow-up survey (Time 4, T4; losses to follow-up are reported in the Results section).

The inclusion criteria of the children were as follows: (1) being under 16 years of age at the baseline survey; (2) registered as a "Precision Student," which is the local government's term for students coming from poor families; (3) have a family monthly income below 3,000 yuan; and (4) understand the questionnaire. The exclusion criteria were as follows: (1) students who had a major physical illness or (2) students who had a history of psychiatric conditions.

\section{Measures}

\section{Family Cumulative Risk}

Concurring with previous research (Evans et al., 2013; Evans and Cassells, 2014), we selected six representative risk factors to evaluate FCR in our sample at T1, adopting classified variables (1 $=$ risky, $0=$ risk-free). Specifically, FCR covered family structure risk (1 factor), family resources risk (2 factors), and family atmosphere risk (3 factors); these factors were derived based on prior research (Buehler and Gerard, 2013).

Family structure risk was determined by family type. The situation was considered risky (i.e., coded as 1) when the child lived without their biological parents; otherwise, it was considered as risk-free (i.e., coded as 0 ; the coding for risk, 1 , and risk-free, 0, was similar for all measures).

Family resource risk was determined based on parental education level and family economic stress. Parental education level was coded as 1 when parents had at or below a high school, technical secondary school, or vocational school education; parents with higher education levels were coded as 0 . Family economic stress was assessed using the Economic Stress Questionnaire (Wadsworth and Compas, 2003), asking whether the family experienced economic stress in the past year. It was measured using four items (e.g., "My family doesn't have enough money to buy new clothes"), which were measured on a fivepoint Likert scale ( $1=$ "Never," 5 = "Nearly always"); higher scores reflect severe economic stress (Cronbach's $\alpha=0.81$ ). Upon calculating the total score of all items, we coded scores in the top quartile as 1 ; lower scores were coded as 0 .

Family atmosphere risk was measured based on child-parent interaction, family function, and parental rearing style. Childparent interaction was measured using one question: "How many hours per week do you spend interacting with your parents (e.g., playing and talking)?" It was measured on a four-point scale $(1=$ $0-3 h ; 2=3-5 h ; 3=5-7 \mathrm{~h}$; and $4=$ more than $7 \mathrm{~h}$ ), and scores of 1 (i.e., $0-3 \mathrm{~h}$ per week) were coded as 1 ; otherwise, they were coded as 0 .

Family function was measured using the Family APGAR Index (Smilkstein, 1984, 1993). It comprises five items addressing the following domains: adaptation, partnership, growth, affection, and resolve. This instrument uses a threepoint Likert scale $(0=$ "Rarely" to $2=$ "Often"), with lower total scores indicating lower family care levels (Cronbach's $\alpha=0.80$ ). Total scores of 7-10 indicated good family function, being coded as 0 ; total scores of $0-6$ suggested moderate to severe family dysfunction, being coded as 1 .

Parental rearing style was measured using the Parental Bonding Instrument (PBI; Mackenzie et al., 2011). It comprises two subscales: the mother rearing style (PBI-M, Cronbach's $\alpha=$ 0.78 ) and the father rearing style (PBI-F, Cronbach's $\alpha=0.81$ ). The 23 items in each subscale were measured on a scale ranging from 1 ("Strongly disagree") to 4 ("Strongly agree") regarding the described rearing style. Different total scores defined four types of parental rearing styles: authoritative, democratic, autocratic, and permissive (Parker et al., 1979). Adolescents experiencing either autocratic or permissive rearing styles were coded as 1 ; meanwhile, authoritative or permissive rearing styles were coded as 0 .

\section{Hope}

Hope levels were measured at T1 and T4 using the Children's Hope Scale (CHS; Snyder et al., 1997). It comprises six items addressing two domains: agency and pathway thinking. The response scale ranged from 1 ("None of the time") to 6 ("All of the time"), where higher scores indicated higher hope levels. The Chinese version of the CHS, upon being tested among Chinese children, showed adequate psychometric properties (Zhao and Sun, 2011). In our study, Cronbach's $\alpha$ was 0.79 at T1 and 0.84 at T4.

\section{Psychological Difficulties}

The Strengths and Difficulties Questionnaire-Difficulties subscale (SDQ-D) was used to assess the psychological difficulties of children for 6 months between T1 and T3. It addressed the following domains: hyperactivity-inattention (5 items), emotional symptoms (5 items), peer problems (5 items), and conduct problems (5 items) (Goodman et al., 1998). The response scale ranged from 0 ("Not true") to 2 ("Certainly true"), and higher scores indicated a higher psychological difficulty. The Chinese version of the SDQ-D showed good applicability in the Chinese population (Yao et al., 2009). In our study, Cronbach's $\alpha$ was 0.86 .

\section{Self-Efficacy}

Self-efficacy was measured using the General Self-Efficacy Scale (GSES), at T1, T2, and T3. The measure comprises 10 items, which are responded to on a four-point Likert scale; higher scores indicate higher self-efficacy (Cheung and Sun, 1999). In our study, Cronbach's $\alpha$ were $0.81,0.78$, and 0.83 at T1, T2, and T3, respectively.

\section{Procedure}

At T1, all participants and their guardians received a standard letter of invitation. We obtained informed consent from all children and guardians before survey onset. Each participant and their guardians were also informed that they would receive a compensation of $50 \mathrm{RMB}$ after survey completion. Students completed the questionnaire in a private meeting room, without any other students in it. One researcher remained in the meeting room with the student and answered the procedural questions. Participants were told that they could withdraw participation at 
any time, for any reason, and that they would be given contact information for relevant mental health services if they ever needed support. All children who partook in the survey at T1 were invited to participate in the follow-up surveys (i.e., T2-T4). According to the theoretical hypothesis of the introduction, we assessed cumulative ecological risk of children in T1, measured hope of children in T4, and measured the mediating variable (psychological difficulties), and moderator variable (self-efficacy) in T2 and T3. Because the surveys at T2 and T3 were conducted in spring and autumn, to avoid seasonal effects, we used the average values of mediating variables at $\mathrm{T} 2$ and $\mathrm{T} 3$.

\section{Statistical Analysis}

The analyses were conducted using IBM SPSS Statistics version 23.0. We performed descriptive statistics to determine the sociodemographic characteristics and FCR. Then, we used Pearson's correlations to examine the associations between FCR and other variables of interest.

To examine common method variance before beginning regression analysis (Johnson et al., 2011), we conducted Harman's one-factor test. We tested the moderation and mediation hypotheses using PROCESS (Hayes, 2017). Bootstrap analysis was conducted with 5,000 iterations to estimate the size of the effects of each model, using 95\% confidence intervals. First, we tested the mediation effect: we entered FCR at T1 (T1 FCR) as the predictor, the mean psychological difficulty scores at T2 and T3 (TM psychological difficulty) as the mediator, and hope at T4 as the outcome. We used the following control variables in the regression analysis: sex, psychological difficulties at T1 (T1 psychological difficulty), and hope at T1. Second, based on the mediation model results, we tested the moderated mediation hypotheses. We entered the mean self-efficacy scores at T2 and T3 as the moderator, while the self-efficacy score at $\mathrm{T} 1$ was used in the regression analysis as an additional covariate. Then, to explore the TM self-efficacy level at which the interaction between T1 FCR and TM psychological difficulties became significant, we calculated simple slopes for low TM selfefficacy (M-SD) and high TM self-efficacy $(M+S D)$ separately. The statistical significance was set at $p<0.05$.

\section{RESULTS}

\section{Sample Description}

At T1, T2, T3, and T4, 504, 473, 419, and 392 children from low-income families completed the survey. The samples at each follow-up survey did not differ in sex, T1 FCR, T1 psychological difficulties, T1 self-efficacy, and T1 hope scores $(p>0.05$ for all). At T4, the sample comprised $242(61.7 \%)$ women and 150 (38.3\%) men aged $11-15$ years, with a mean age of 12.66 (SD $=1.23$ ). Other sociodemographic characteristics are presented in Table 1.

\section{Family Cumulative Risk Characteristics Among Chinese Children From Low-Income Families}

Most children in our sample $(89.3 \%)$ reported having a family with moderate or severe dysfunction, and more than $60 \%$
TABLE 1 | Descriptive sociodemographic variables.

\begin{tabular}{|c|c|c|}
\hline $\begin{array}{l}\text { Sociodemographic } \\
\text { variables }\end{array}$ & Note & $n(\%)$ \\
\hline Age & Year[M(SD)] & $12.66(1.23)$ \\
\hline Gender & Female & 242(61.7) \\
\hline $\begin{array}{l}\text { Place of } \\
\text { residence }\end{array}$ & Rural & 286(73.0) \\
\hline $\begin{array}{l}\text { Single-child } \\
\text { family }\end{array}$ & Yes & $66(16.8)$ \\
\hline Ethnicity & Ethnic Han & $319(81.4)$ \\
\hline \multicolumn{3}{|l|}{$\begin{array}{l}\text { Family } \\
\text { cumulative } \\
\text { risk }\end{array}$} \\
\hline $\begin{array}{l}\text { Family } \\
\text { structure risk }\end{array}$ & $\begin{array}{l}\text { (1) Living without the } \\
\text { biological parents }\end{array}$ & $88(22.4)$ \\
\hline \multirow{2}{*}{$\begin{array}{l}\text { Family } \\
\text { resources risk }\end{array}$} & (1) Low educational level of parents & 259(66.1) \\
\hline & (2) High family economic stress & 116(29.6) \\
\hline \multirow{3}{*}{$\begin{array}{l}\text { Family } \\
\text { atmosphere } \\
\text { risk }\end{array}$} & (1) Lack of interaction with parents & 252(64.3) \\
\hline & $\begin{array}{l}\text { (2) Family with moderate or } \\
\text { severe dysfunction }\end{array}$ & 350(89.3) \\
\hline & $\begin{array}{l}\text { (3) Autocratic or permissive parental } \\
\text { rearing styles. }\end{array}$ & 130(33.2) \\
\hline
\end{tabular}

reported having parents with low education and lacking in parental interaction. The least prevalent family risk was living without biological parents (22.4\%; see Table $\mathbf{1})$.

\section{Correlation Analysis}

We found negatively significant correlations between hope and FCR scores; hope and psychological difficulties scores; selfefficacy, and FCR scores; and self-efficacy and psychological difficulty scores (Table 2). We also observed a significant positive correlation between hope and self-efficacy scores.

\section{Mediation Analyses}

After conducting an exploratory factor analysis (EFA), we found 14 factors with eigenvalues $>1$. Moreover, the first factor accounted for only $14.33 \%$ of the total variance. Hence, our study was not affected by the common method bias.

We conducted the mediation analysis using Model 4 in PROCESS. The T1 FCR scores did not directly predict T4 hope scores ( $b=0.01, p=0.17$; Table 3). However, the main effect of T1 FCR and TM psychological difficulties scores was significant and was positively associated $(b=0.17, p<0.01)$. There was also a significantly negative effect of TM psychological difficulties on T4 hope $(b=-0.27, p<0.01)$. Additionally, when controlling for sex, T1 hope, and T1 psychological difficulties, the indirect effect of TM psychological difficulties on the relationship between T1 FCR and T4 hope scores was significant $(b=-0.05,95 \%$ $\mathrm{CI}=-0.08 \sim-0.02)$. Therefore, psychological difficulties fully mediated the effects of FCR on hope among children from low-income families in our sample. 
TABLE 2 | Descriptive statistics and correlation analyses.

\begin{tabular}{|c|c|c|c|c|c|c|c|c|c|}
\hline Variables & $M \pm S D$ & 1 & 2 & 3 & 4 & 5 & 6 & 7 & 8 \\
\hline 1.T1 Family cumulative risk & $3.05 \pm 1.18$ & - & & & & & & & \\
\hline 2,T1 Psychological-difficulties & $31.66 \pm 5.74$ & 0.09 & - & & & & & & \\
\hline 3.T2 Psychological-difficulties & $31.87 \pm 5.68$ & $0.14^{\star \star}$ & $0.56^{\star \star}$ & - & & & & & \\
\hline 4.T3 Psychological-difficulties & $32.30 \pm 5.36$ & $0.23^{\star \star}$ & $0.43^{\star \star}$ & $0.53^{\star \star}$ & - & & & & \\
\hline 5.T1 Self-Efficacy & $25.78 \pm 5.02$ & -0.05 & $-0.32^{\star \star}$ & $-0.24^{\star \star}$ & $-0.19^{\star *}$ & - & & & \\
\hline 6.T2 Self-Efficacy & $26.24 \pm 5.26$ & $-0.11^{\star}$ & $-0.29^{\star \star}$ & $-0.30^{\star \star}$ & $-0.22^{\star \star}$ & $0.40^{\star \star}$ & - & & \\
\hline 7.T3 Self-Efficacy & $26.70 \pm 4.65$ & -0.05 & $-0.23^{\star \star}$ & $-0.26^{\star \star}$ & $-0.37^{\star \star}$ & $0.28^{\star \star}$ & $0.36^{\star \star}$ & - & \\
\hline 8.T1Норе & $21.86 \pm 5.46$ & -0.02 & $-0.28^{\star \star}$ & $-0.19^{\star \star}$ & $-0.14^{\star \star}$ & $0.64^{\star \star}$ & $0.24^{\star \star}$ & 0.02 & - \\
\hline 9.T4 Hope & $21.66 \pm 5.56$ & -0.06 & $-0.19^{\star \star}$ & $-0.26^{\star \star}$ & $-0.27^{\star *}$ & $0.30^{\star \star}$ & $0.36^{\star \star}$ & $0.18^{\star \star}$ & $0.29^{\star \star}$ \\
\hline
\end{tabular}

T1: Time 1; T2: Time 2; T3: Time3; T4: Time4; ${ }^{*} p<0.05 ;{ }^{* *} p<0.001$.

TABLE 3 | Regression results of testing the mediating model.

\begin{tabular}{|c|c|c|c|c|c|c|c|c|}
\hline \multirow[t]{2}{*}{ Variables } & \multirow[b]{2}{*}{$\boldsymbol{b}$} & \multicolumn{2}{|c|}{ Step 1} & \multirow[b]{2}{*}{$95 \% \mathrm{Cl}$} & \multirow[b]{2}{*}{$b$} & \multicolumn{2}{|c|}{ Step 2} & \multirow[b]{2}{*}{$95 \% \mathrm{Cl}$} \\
\hline & & S.E. & $t$ & & & S.E. & $t$ & \\
\hline Gender & 0.13 & 0.09 & 1.44 & $-0.05,0.31$ & -0.26 & 0.10 & $-2.56^{\star}$ & $-0.47,-0.06$ \\
\hline T1 Hope & 0.01 & 0.05 & 0.12 & $-0.08,0.10$ & 0.24 & 0.05 & $4.72^{\star \star}$ & $0.14,0.35$ \\
\hline T1 Psychological difficulties & 0.53 & 0.05 & $11.32^{\star \star}$ & $0.44,0.63$ & 0.01 & 0.06 & 0.17 & $-0.11,0.13$ \\
\hline T1 Family cumulative risk & 0.17 & 0.05 & $3.84^{\star \star}$ & $0.08,0.26$ & 0.01 & 0.05 & 0.16 & $-0.09,0.11$ \\
\hline TM Psychological difficulties & & & & & -0.27 & 0.06 & $-4.57^{\star \star}$ & $-0.41,-0.16$ \\
\hline$F$ & & $42.34^{\star \star}$ & & & & $14.82^{\star \star}$ & & \\
\hline$R^{2}$ & & 0.34 & & & & 0.19 & & \\
\hline
\end{tabular}

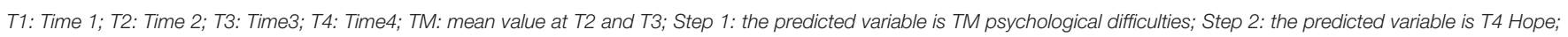
${ }^{*} p<0.05 ;{ }^{* *} p<0.001$.

\section{Moderation Analyses}

To further reveal the moderating effect of self-efficacy between psychological difficulty and hope, the positive and negative standard deviations of the mean value of self-efficacy were taken as the dividing point. The participants with scores higher than one standard deviation were classified as high self-efficacy group, while those with scores lower than one standard deviation were classified as low selfefficacy group. The specific moderating effect is shown in Figure 2.

The moderation model was significant, with self-efficacy as the outcome (Figure 1). Only the interaction between selfefficacy and psychological difficulties predicted T4 hope in the moderated mediation models. Hence, self-efficacy moderated the relationship between T1 FCR and T4 hope. This implies that the indirect effect of T1 FCR on T4 hope, mediated by TM psychological difficulties, significantly differed by self-efficacy. We observed, through simple slope analyses, that there was a weak negative relationship between TM psychological difficulties and $\mathrm{T} 4$ hope at a low level of self-efficacy $(b=-0.12, \mathrm{SE}=$ $0.07, p=0.09,95 \% \mathrm{CI}=-0.26,0.02)$. Meanwhile, we found a strong significant negative relationship at high levels of selfefficacy $(b=-0.29, \mathrm{SE}=0.08, p<0.001,95 \% \mathrm{CI}=-0.46,-0.13$; Figure 2).

\section{DISCUSSION}

\section{Family Cumulative Risk Status Among Chinese Children From Low-Income Families}

Previous studies have found that children from low-income families face twice as many risks as the general population (Anda et al., 2010), raising their risk index for emotional and behavioral problems two to five times more than that of other children (Freeman and Pamela, 2014). Therefore, when examining the impact of poverty on the mental health of children, we must also consider the cumulative effects of other risk factors. Our results showed that most Chinese children from low-income families experienced family risk; this concurs with existing research (Burlaka et al., 2015; Asfour et al., 2017; Weitkamp and Seiffge-Krenke, 2019). Moreover, our findings suggested that our sample often faced multiple and cumulative family risk factors simultaneously. Compared with the general population, the risk of family resources related to the economy is particularly serious for children in low-income families. Due to low education levels, it is difficult for parents to obtain high-income or stable jobs, resulting in less investment in the upbringing of children. Additionally, the living environment needs improvement (Gao and Han, 2016; Boe et al., 2018). We hypothesized that the 


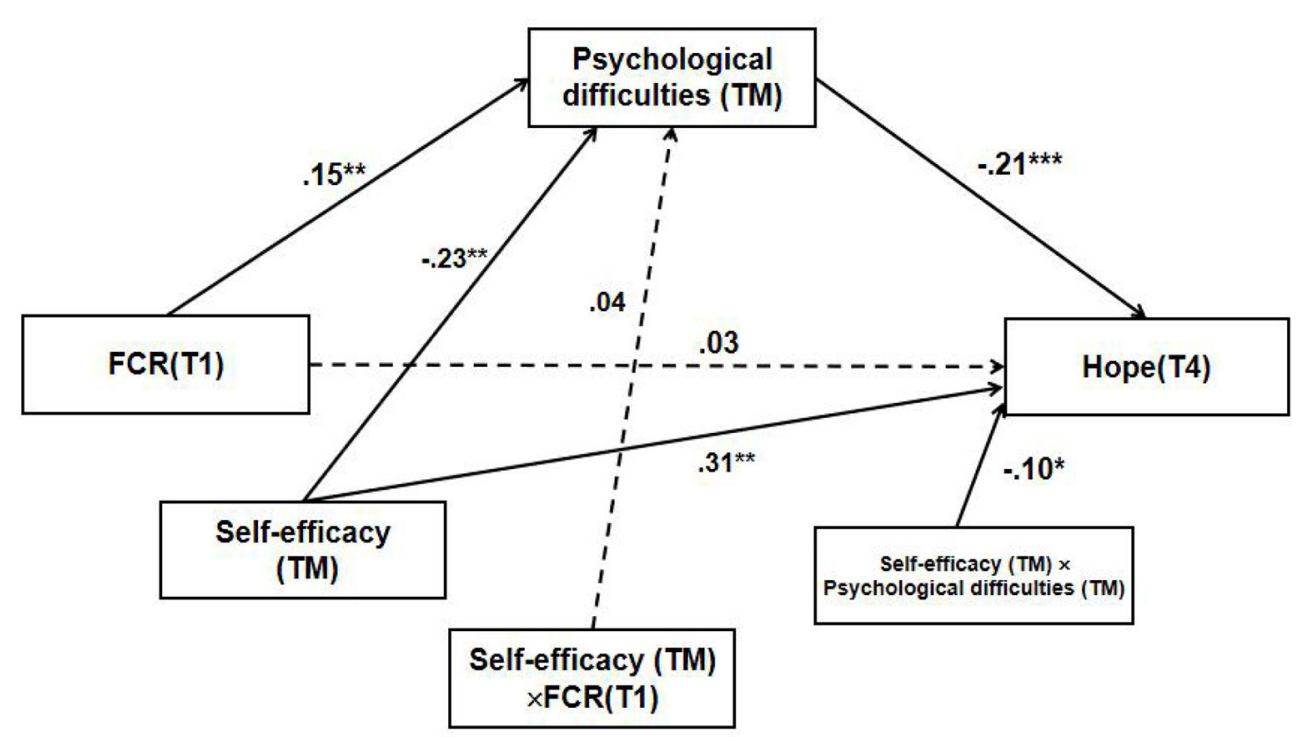

FIGURE 1 | Results of the moderated mediation analysis. FCR, Family cumulative risk, ${ }^{\star} p>0.05,{ }^{* \star} p<0.01,{ }^{\star \star *} p<0.001$.

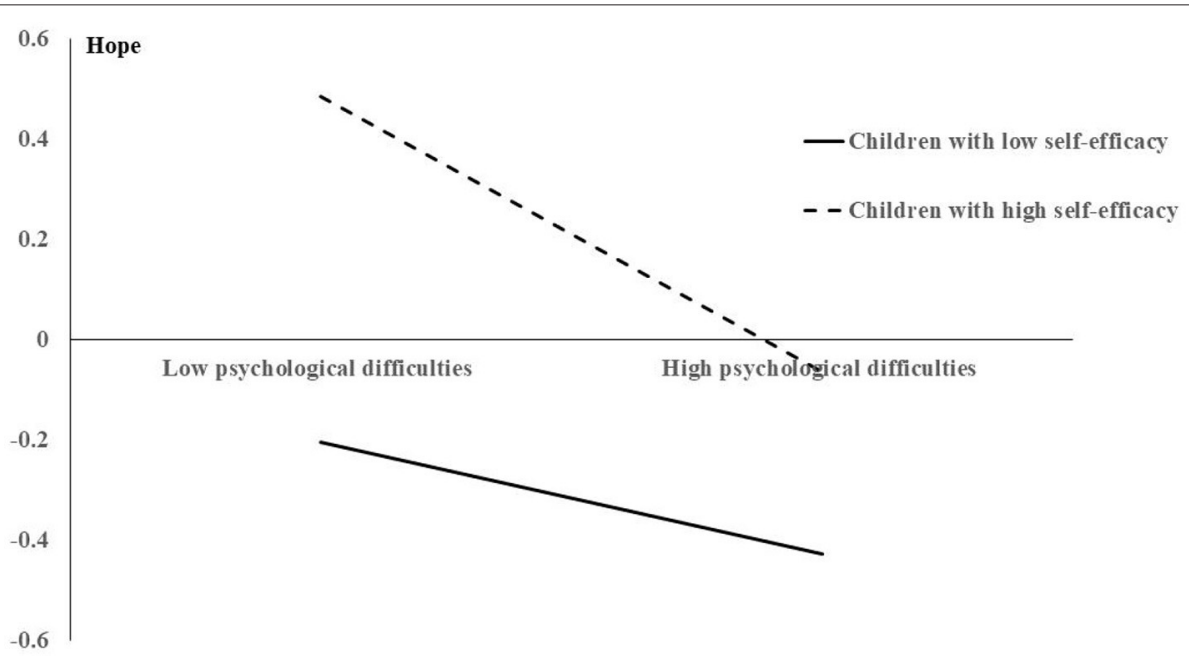

FIGURE 2 | The interaction between self-efficacy and psychological difficulties in predicting hope.

impact of family poverty on parents migrated into the parentchild interactions. Indeed, a study showed that the risk of economic stress is likely to affect the psychological adaptation of parents, resulting in various increased risk factors in the familial experiences of the child, such as family care, parental marital quality, and parenting style (Masarik and Conger, 2017). Therefore, to understand the situations of children in low-income families, stakeholders should observe FCR of children and the possible effects on the child.

\section{The Relationship Between FCR, Psychological Difficulties, and Child Hope}

The most striking finding of this study was that psychological difficulties fully mediated the relationship between FCR and hope during the entire 2-year study period. Additionally, FCR had a positive effect on psychological difficulties. Previous studies have suggested that in poor families, parents must cope with continuous survival and economic pressures, diminishing their energy and patience, thereafter, hindering their ability to pay attention to and meet the emotional needs of their children. Then, when children do not have their normal material and emotional needs relevantly met, they often become stressed and insecure, leading to psychological difficulties (e.g., emotional problems) (Evans and Kim, 2013). Meanwhile, regarding hope, early theories have suggested that hope is not innate; it is acquired and altered through learned experiences (Snyder et al., 1991). Hence, we speculated that psychological difficulties in children could cause them to experience stress; thereafter, stress reduces 
positive psychological resources of children, finally inhibiting the development of hope. Our results supported the past research (Fredrickson, 2001), which has demonstrated that when children experience more positive emotions, they become more focused and open; the study describes that, in this state, children feel an urge to try new approaches, develop new problem-solving strategies, and make creative efforts. Another study found that the pathways between depression and hope are significant ( $\mathrm{Li}$ et al., 2018). To summarize, by encouraging individuals to think positively about the possible outcomes of various actions, positive emotions can expand the scope of attention, cognition, and action of an individual; this may allow individuals to achieve a higher level of pathway thinking. Positive emotions can also strengthen the lasting physical and psychological resources of an individual, giving them stronger motivation to pursue goals and achieve a higher level of agency thinking.

Moreover, positive family environments showed a significant impact on an orientation of a child toward and planning of future goals; specifically, children from families with low family risk tended to have more positive and clear future goals, whereas their counterparts from families with high family risk tended to have negative and vague future goals (Griskevicius et al., 2011; Schroder et al., 2011). From this, we can infer that FCR has a direct impact on children's development of hope. Contrarily, our findings showed that FCR did not significantly predict the long-term hope. This could be because most children in our sample spent most of their time at school. When constantly separated from the family environment, over time, its impact may gradually weaken. Hence, the school environment, where many Chinese children spend most of their time, may have a greater influence on the children's development of hope. Concurrently, poverty may affect children's levels of satisfaction and connection with their school, affecting the quality of their interpersonal communication and influencing their mental health (ClementsNolle and Waddington, 2019; Saunders and Brown, 2020).

\section{A Drop in the Ocean Effect of Self-Efficacy}

Our evidence showed that high self-efficacy was associated with decreased psychological difficulty levels and elevated hope levels. This concurs with the literature, which indicated that self-efficacy significantly predicts mental health; specifically, individuals with high self-efficacy tended to have higher levels of positive mental health factors (e.g., life satisfaction, self-esteem, and positive emotions) and lower levels of negative factors (e.g., loneliness, depression, anxiety, and negative emotions) (Jiang et al., 2015; Gao et al., 2017; Wang and Zhang, 2017). Self-efficacy was also shown to have a significant positive effect on hope, and individuals with high self-efficacy had clearer goals and achieved them more effectively (Snyder, 2002; Phan, 2013).

Our findings showed that self-efficacy moderated the association between psychological difficulties and hope; specifically, this moderation supported a prior notion: the "drop in the ocean effect" (Li et al., 2012). Namely, the protective effect of high self-efficacy worked only when psychological difficulties were at low levels. When psychological difficulties were at high levels, the buffering effect of self-efficacy on FCR was gradually weakened and eventually lost. Based on prior research (Anderson et al., 2006; Wiederkehr et al., 2015), we believe that, in children from low-income families, a higher level of FCR may lead to more psychological difficulties and also hinder self-efficacy development.

This understanding allows us to speculate that most Chinese children in low-income families are low in self-efficacy; if accurate, this supposition entails that in such poverty settings, only children with low individual psychological risk levels may gain any protection through self-efficacy. Therefore, when external or internal psychological risks are too high in children from low-income families, interventions focused on increasing positive psychological aspects may not provide a sustainable impact on their psychological state.

\section{Clinical Consideration}

According to the results of this study, the following considerations can be made when designing positive interventions to promote the level of hope in children from low-income families:

It has been demonstrated that the cumulative family risk affects the level of hope in children from low-income families. Therefore, we can consider reducing family risk factors to increase levels of hope in children. For example, parents may be advised to devote more time to parent-child communication. Second, we may also begin with an intervention for the psychological difficulties that children in low-income families face. We can mitigate the negative impact of family risk on children's future levels of hope by improving their mental health levels. Finally, the "a drop in the ocean" effect of self-efficacy reminds us that while we strive to improve children's self-efficacy, we must also recognize the limitations of the protective role of self-efficacy and pay attention to implementing interventions that help reduce family risk.

\section{Limitations}

First, the sample shedding rate in our study was relatively high, which may have biased the results. One primary reason for the sample attrition was that the parents of many Chinese children from low-income families are often migrant workers; hence, their children often have high mobility and school transfer rates. These characteristics hindered our ability to retain the sample for the follow-up surveys. Second, the reported psychological difficulties were measured through self-reported questionnaires; these are subject to the influence of social desirability. Third, we believe that important co-occurring risk factors (e.g., peer relations or social support networks), which have effects that cannot be analyzed via statistical analyses, may have influenced our findings. Finally, there was no longitudinal survey of children from middle-income families for comparative analysis in our study.

\section{CONCLUSIONS}

The present longitudinal study was the first to support the potential moderating (self-efficacy) and mediating (psychological difficulties) factors of the relationship between FCR and hope among children from low-income families in China. Our findings suggested that psychological difficulties mediate the aforementioned relationship; namely, FCR seemingly predicted 
hope levels via psychological difficulties in our sample. Selfefficacy, meanwhile, served as a moderator between psychological difficulties and hope. Specifically, self-efficacy buffered the impact of psychological difficulties on hope, albeit the buffering effect was smaller if psychological difficulties were higher. Overall, family risk factors and psychological difficulties were shown to be key predictors of hope among Chinese children from low-income families. Hence, it is important not to be overly optimistic about the protective role of self-efficacy for children in such settings.

\section{DATA AVAILABILITY STATEMENT}

The raw data supporting the conclusions of this article will be made available by the authors, without undue reservation.

\section{ETHICS STATEMENT}

The studies involving human participants were reviewed and approved by Ethics Committees of Hunan Key Laboratory

\section{REFERENCES}

Anda, R. F., Butchart, A., Felitti, V. J., and Brown, D. W. (2010). Building a framework for global surveillance of the public health implications of adverse childhood experiences. Am. J. Prev. Med. 39, 93-98. doi: 10.1016/j.amepre.2010.03.015

Anderson, E. S., Wojcik, J. R., Winett, R. A., and Williams, D. M. (2006). Socialcognitive determinants of physical activity: the influence of social support, self-efficacy, outcome expectations, and self-regulation among participants in a church-based health promotion study. Health Psychol. 25, 510-520. doi: 10.1037/0278-6133.25.4.510

Arnau, R. C., Rosen, D. H., Finch, J. F., Rhudy, J. L., and Fortunato, V. J. (2007). Longitudinal effects of hope on depression and anxiety: a latent variable analysis. J. Pers. 75, 43-64. doi: 10.1111/j.1467-6494.2006.00432.x

Asfour, L., Huang, S., Ocasio, M. A., Perrino, T., Schwartz, S. J., Feaster, D. J., et al. (2017). Association between socio-ecological risk factor clustering and mental, emotional, and behavioral problems in hispanic adolescents. J. Child Fam. Stud. 26, 1266-1273. doi: 10.1007/s10826-016-0641-0

Barrows, J., Dunn, S., and Lloyd, C. A. (2013). Anxiety, self-efficacy, and college exam grades. Univ. J. Educ. Res. 3, 204-208. doi: 10.13189/ujer.2013.010310

Boe, T., Serlachius, A. S., Sivertsen, B., Petrie, K. J., and Hysing, M. (2018). Cumulative effects of negative life events and family stress on children's mental health: the Bergen Child Study. Soc. Psychiatry Psychiatr. Epidemiol. 53, 1-9. doi: 10.1007/s00127-017-1451-4

Bosmans, M. W. G., Van, D. K. L. M., and Van, D. V. P. G. (2015). Personality traits as predictors of trauma-related coping self-efficacy: a three-wave prospective study. Person. Individ. Diff. 76, 44-48. doi: 10.1016/j.paid.2014.11.052

Brown, P. H., and Park, A. (2002). Education and poverty in rural China. Econ. Educ. Rev. 21, 523-547. doi: 10.1016/S0272-7757(01)00040-1

Buehler, C., and Gerard, J. M. (2013). Cumulative family risk predicts increases in adjustment difficulties across early adolescence. J. Youth Adolesc. 42, 905-920. doi: 10.1007/s10964-012-9806-3

Burlaka, V., Bermann, E. A., and Graham-Bermann, S. A. (2015). Internalizing problems in at-risk preschoolers: associations with child and mother risk factors. J. Child Fam. Stud. 24, 2653-2660. doi: 10.1007/s10826-0140067-5

Burlaka, V., Kim, Y. J., Crutchfield, J. M., Lefmann, T. A., and Kay, E. S. (2017). Predictors of internalizing behaviors in Ukrainian children. Fam. Relat. 66, 854-866. doi: 10.1111/fare.12289

Cheung, S. K., and Sun, S. Y. (1999). Assessment of optimistic self-beliefs: further validation of the Chinese version of the general self-efficacy scale. Psychol. Rep. 85, 1221-1224. doi: 10.2466/pr0.1999.85.3f.1221 of Children's Psychological Development and Brain Cognitive Science, Hunan First Normal University. Written informed consent to participate in this study was provided by the participants' legal guardian/next of kin.

\section{AUTHOR CONTRIBUTIONS}

$\mathrm{XY}$ and $\mathrm{YH}$ was mainly responsible for the overall conception and design of this study. DW wrote the manuscript and carried out the statistical analysis. ZL carried out the investigation and data collation work. YH carried out the language polishing for the manuscript. All authors contributed to the article and approved the submitted version.

\section{FUNDING}

This work was supported by Scientific research project of Hunan Education Department (17K049). A key funded project of Hunan Educational Science Planning in 2019 (XJK19AXL003).

Clements-Nolle, K., and Waddington, R. (2019). Adverse childhood experiences and psychological distress in juvenile offenders: the protective influence of resilience and youth assets. J. Adolesc. Health 64, 49-55. doi: 10.1016/j.jadohealth.2018.09.025

Davidson, O. B., Feldman, D. B., and Margalit, M. (2012). A focused intervention for 1st-year college students: promoting hope, sense of coherence, and selfefficacy. J. Psychol. 146, 333-352. doi: 10.1080/00223980.2011.634862

Evans, G. W., and Cassells, R. C. (2014). Childhood poverty, cumulative risk exposure, and mental health in emerging adults. Clin. Psychol. Sci. 2, 287-296. doi: $10.1177 / 2167702613501496$

Evans, G. W., and Kim, P. (2013). Childhood poverty, chronic stress, selfregulation, and coping. Child Dev. Perspect. 7, 43-48. doi: 10.1111/cdep.12013

Evans, G. W., Li, D., and Whipple, S. S. (2013). Cumulative risk and child development. Psychol. Bull. 139, 1342-1396. doi: 10.1037/a0031808

Fredrickson, B. L. (2001). The role of positive emotions in positive psychology. The broaden-and-build theory of positive emotions. Am. Psychol. 56, 218-226. doi: 10.1037/0003-066X.56.3.218

Freeman, C., and Pamela, A. (2014). Prevalence and relationship between adverse childhood experiences and child behavior among young children. Infant Ment. Health J. 35, 544-554. doi: 10.1002/imhj.21460

Gallagher, M. W., Marques, S. C., and Lopez, S. J. (2017). Hope and the academic trajectory of college students. J. Happiness Stud. 18, 341-352. doi: 10.1007/s10902-016-9727-z

Gao, M., and Han, Z. R. (2016). Family expressiveness mediates the relation between cumulative family risks and children's emotion regulation in a Chinese sample. J. Child Fam. Stud. 25, 1570-1580. doi: 10.1007/s10826-015-0335-z

Gao, S., Assink, M., Cipriani, A., and Lin, K. (2017). Associations between rejection sensitivity and mental health outcomes: a meta-analytic review. Clin. Psychol. Rev. 57, 59-74. doi: 10.1016/j.cpr.2017.08.007

Goodman, R., Meltzer, H., and Bailey, V. (1998). The strengths and difficulties questionnaire: a pilot study on the validity of the self-report version. Eur. Child Adolesc. Psychiatry 7, 125-130. doi: 10.1007/s007870050057

Griskevicius, V., Tybur, J. M., Delton, A. W., and Robertson, T. E. (2011). The influence of mortality and socioeconomic status on risk and delayed rewards: a life history theory approach. J. Pers. Soc. Psychol. 100, 1015-1026. doi: $10.1037 / \mathrm{a} 0022403$

Hayes, A. F. (2017). Introduction to Mediation, Moderation, and Conditional Process Analysis: A Regression-Based Approach. New York, NY: Guilford publications.

Heuven, E., Bakker, A. B., Schaufeli, W. B., and Huisman, N. (2006). The role of self-efficacy in performing emotion work. J. Vocat. Behav. 69, 222-235. doi: 10.1016/j.jvb.2006.03.002 
Hodgkinson, S., Godoy, L., Beers, L. S., and Lewin, A. (2017). Improving mental health access for low-income children and families in the primary care setting. Pediatrics 139:1175. doi: 10.1542/peds.2015-1175

Jiang, Z., Hu, X., Wang, Z., and Jiang, X. (2015). Career decision self-efficacy and life satisfaction in china: an empirical analysis. Soc. Indic. Res. 132, 1-18. doi: 10.1007/s11205-015-1201-5

Johnson, R. E., Rosen, C. C., and Djurdjevic, E. (2011). Assessing the impact of common method variance on higher order multidimensional constructs. J. Appl. Psychol. 96, 744-761. doi: 10.1037/a0021504

Li, D., Zhang, W., Li, X., Li, N., and Ye, B. (2012). Gratitude and suicidal ideation and suicide attempts among Chinese adolescents: direct, mediated, and moderated effects. J. Adolesc. 35, 55-66. doi: 10.1016/j.adolescence.2011. 06.005

Li, Z., Wang, Y., Mao, X., and Yin, X. (2018). Relationship between hope and depression in college students: a cross-lagged regression analysis. Personal. Ment. Health 12, 170-176. doi: 10.1002/pmh.1412

Mackenzie, M. J., Kotch, J. B., Lee, L. C., Augsberger, A., and Hutto, N. (2011). A cumulative ecological-transactional risk model of child maltreatment and behavioral outcomes: reconceptualizing early maltreatment report as risk factor. Child. Youth Serv. Rev. 33, 2392-2398. doi: 10.1016/j.childyouth.2011.08.030

Masarik, A. S., and Conger, R. D. (2017). Stress and child development: a review of the family stress model. Curr. Opin. Psychol. 13, 85-90. doi: 10.1016/j.copsyc.2016.05.008

Masten, A. S., Herbers, J. E., Cutuli, J. J., and Lafavor, T. L. (2008). Promoting competence and resilience in the school context. Prof. School Counsel. 12, 76-84. doi: 10.5330/PSC.n.2010-12.76

McLaughlin, K. A., and Sheridan, M. A. (2016). Beyond cumulative risk: a dimensional approach to childhood adversity. Curr. Dir. Psychol. Sci. 25, 239-245. doi: 10.1177/0963721416655883

Mo, D., Zhang, L., Yi, H., Luo, R., Rozelle, S., and Brinton, C. (2013). School dropouts and conditional cash transfers: evidence from a randomised controlled trial in rural China's junior high schools. J. Dev. Stud. 49, 190-207. doi: 10.1080/00220388.2012.724166

Ouweneel, E., Le Blanc, P. M., and Schaufeli, W. B. (2012). Good morning, good day: a diary study on positive emotions, hope, and work engagement. Hum. Relat. 65, 1129-1154. doi: 10.1177/0018726711429382

Parker, G., Tupling, H., and Brown, L. B. (1979). A parental bonding instrument. Br. J. Med. Psychol. 52, 1-10. doi: 10.1111/j.2044-8341.1979.tb02487.x

Phan, H. P. (2013). Examination of self-efficacy and hope: a developmental approach using latent growth modeling. J. Educ. Res. 106, 93-104. doi: 10.1080/00220671.2012.667008

Saunders, P., and Brown, J. E. (2020). Child poverty, deprivation and well-being: evidence for Australia. Child Indic. Res. 13, 1-18. doi: 10.1007/s12187-019-09643-5

Schroder, E., Schmitt-Rodermund, E., and Arnaud, N. (2011). Career choice intentions of adolescents with a family business background research question. Fam. Bus. Rev. 24, 305-321. doi: 10.1177/0894486511416977

Schwarzer, R. (1994). Optimism, vulnerability, and self-beliefs as healthrelated cognitions: a systematic overview. Psychol. Health 9, 161-180. doi: 10.1080/08870449408407475

Smilkstein, G. (1984). The physician and family function assessment. Fam. Syst. Med. 2, 263-278. doi: 10.1037/h0091661

Smilkstein, G. (1993). Family APGAR analyzed. Fam. Med. 25, 293-294. doi: $10.3138 /$ jcfs. 25.2 .293

Snyder, C. R. (1995). Conceptualizing, measuring, and nurturing hope. J. Counsel. Dev. 73, 355-360. doi: 10.1002/j.1556-6676.1995.tb01764.x

Snyder, C. R. (2002). Hope theory: rainbows in the mind. Pcychol. Inq. 13, 249-275. doi: 10.1207/S15327965PLI1304_01

Snyder, C. R., Harris, C., Anderson, J. R., Holleran, S. A., Irving, L. M., Sigmon, S. T., et al. (1991). The will and the ways: development and validation of an individual-differences measure of hope. J. Person. Soc. Psychol. 60, 570-585. doi: 10.1037/0022-3514.60.4.570

Snyder, C. R., Hoza, B., Pelham, W. E., Rapoff, M., Ware, L., Danovsky, M., et al. (1997). The development and validation of the Children's Hope Scale. J. Pediatr. Psychol. 22, 399-421. doi: 10.1093/jpepsy/22.3.399

Wadsworth, M. E., and Achenbach, T. M. (2005). Explaining the link between low socioeconomic status and psychopathology: testing two mechanisms of the social causation hypothesis. J. Consult. Clin. Psychol. 73, 1146-1153. doi: 10.1037/0022-006X.73.6.1146

Wadsworth, M. E., and Compas, B. E. (2003). Coping with family conflict and economic strain: the adolescent perspective. J. Res. Adolesc. 12, 243-274. doi: 10.1111/1532-7795.00033

Wang, H., Yang, C., He, F., Shi, Y., Qu, Q., Rozelle, S., et al. (2015). Mental health and dropout behavior: a cross-sectional study of junior high students in northwest rural China. Int. J. Educ. Dev. 41, 1-12. doi: 10.1016/j.ijedudev.2014.12.005

Wang, Y., and Zhang, B. (2017). The dual model of perfectionism and depression among Chinese University students. S. Afr. J. Psychiatr. 23:1025. doi: 10.4102/sajpsychiatry.v23i0.1025

Weitkamp, K., and Seiffge-Krenke, I. (2019). The association between parental rearing dimensions and adolescent psychopathology: a cross-cultural study. J. Youth Adolesc. 48, 469-483. doi: 10.1007/s10964-018-0928-0

Wiederkehr, V., Darnon, C., Chazal, S., Guimond, S., and Martinot, D. (2015). From social class to self-efficacy: internalization of low social status pupils' school performance. Soc. Psychol. Educ. 18, 769-784. doi: 10.1007/s11218-015-9308-8

Wright, A. G. C., Hallquist, M. N., Beeney, J. E., and Pilkonis, P. A. (2013). Borderline personality pathology and the stability of interpersonal problems. J. Abnorm. Psychol. 122, 1094-1100. doi: 10.1037/a0034658

Yao, S., Zhang, C., Zhu, X., Jing, X., McWhinnie, C. M., and Abela, J. R. Z. (2009). Measuring Adolescent psychopathology: psychometric properties of the self-report strengths and difficulties questionnaire in a sample of Chinese adolescents. J. Adolesc. Health 45, 55-62. doi: 10.1016/j.jadohealth.2008.11.006

Yi, H., Zhang, L., Luo, R., Shi, Y., Mo, D., Chen, X., et al. (2012). Dropping out: why are students leaving junior high in China's poor rural areas? Int. J. Educ. Dev. 32, 555-563. doi: 10.1016/j.ijedudev.2011.09.002

Yin, X., Li, Z., Yuan, Y., and Wang, Z. (2019). Developmental trajectory of hope among late-adolescents: population heterogeneity and the impact of gender and family socioeconomic status. J. Adolesc. 72, 124-131. doi: 10.1016/j.adolescence.2019.03.003

Zhao, B. H., and Sun, Y. (2011). Reliability and validity of the Chinese vision of children's hope scale. Chin. J. Ment. Health 6, 454-459.

Conflict of Interest: The authors declare that the research was conducted in the absence of any commercial or financial relationships that could be construed as a potential conflict of interest.

Publisher's Note: All claims expressed in this article are solely those of the authors and do not necessarily represent those of their affiliated organizations, or those of the publisher, the editors and the reviewers. Any product that may be evaluated in this article, or claim that may be made by its manufacturer, is not guaranteed or endorsed by the publisher.

Copyright (C) 2021 Yin, Wang, Li and Huang. This is an open-access article distributed under the terms of the Creative Commons Attribution License (CC BY). The use, distribution or reproduction in other forums is permitted, provided the original author(s) and the copyright owner(s) are credited and that the original publication in this journal is cited, in accordance with accepted academic practice. No use, distribution or reproduction is permitted which does not comply with these terms. 